\title{
UM NOVO FUTURO
}

Luiz CARlos Mendonça de BARros

\section{RESUMO}

Para explicar o dinamismo da economia brasileira nos últimos anos, é preciso entender as mudanças na economia mundial, principalmente na Ásia. A incorporação de quase um bilhão de asiáticos à economia de mercado provocou uma alteração profunda nas relações de preços entre produtos industriais e commodities agrícolas e minerais, em favor destes últimos. Essa nova dinâmica de preços nos mercados mundiais provocou uma mudança nas contas de nosso comércio exterior, com o aparecimento, a partir de 2004, de saldos comerciais elevadíssimos.

PALAVRAS-CHAVE: commodities; economia brasileira; China; crescimento econômico.

\section{SUMMARY}

To understand the dynamics of Brazilian economy in recent years, one has to assimilate the changes in the world economy, mainly in Asia. The incorporation of almost a billion of Asians into the market economy led to a profound change in the relations of prices between industrial products and mineral and agricultural commodities, in favour of the latter. This new dynamic of prices in international markets had an impact over our external commerce, resulting, since 2004, in very high incomes.

KEYWORDS: commodities; Brazilian Economy; China; economic growth.

Após um período longo, várias décadas, o Brasil finalmente reencontrou o caminho do crescimento econômico sustentado. Entre 2005 e 2008 vamos crescer a uma média anual de $4,5 \%$, e as projeções para os próximos anos mostram a manutenção desta dinâmica. Deixamos para trás a imagem de um país estagnado, sem futuro, e afundado em crises financeiras recorrentes. Hoje o Brasil é visto pela comunidade financeira internacional como uma das economias emergentes de maior potencial de crescimento nas próximas décadas. Este novo posicionamento no cenário internacional ficou caracterizado de forma clara em recente artigo publicado, no jornal espanhol El País, pelo editor-chefe da tradicional e conservadora revista The Economist. 
Muitos se perguntam sobre as causas centrais desta mudança extraordinária da economia brasileira. Outros, mais pessimistas, questionam se esta nova dinâmica é estável, apresentando uma série de desafios - por exemplo, a questão da chamada doença holandesa ${ }^{1}$ - que deveremos enfrentar no futuro. Eu defendo com convicção a tese de que acumulamos, principalmente a partir de 1994, com o Plano Real, uma massa crítica de reformas e de novos valores econômicos ${ }^{2}$ suficientes para deixar para trás as décadas de crises que tivemos a partir de 1975 .

Mas, para explicar o dinamismo dos últimos anos e justificar o otimismo que cerca hoje o futuro de nosso país, precisamos entender as mudanças que estão ocorrendo na economia mundial, principalmente na Ásia. Nesta primeira década do século XXI, um novo pólo dinâmico se desenvolveu, a partir do crescimento da China, no chamado mundo emergente. Hoje, este grupo de países tem uma contribuição no crescimento do PIB mundial igual à dos Estados Unidos e da Europa Unida.

Sem este novo equilíbrio, as reformas econômicas do período FHC e a surpreendente conversão do presidente Lula aos princípios da economia liberal não teriam sido suficientes para possibilitar a virada que vivemos hoje. A incorporação de quase um bilhão de asiáticos, na sua grande maioria de chineses, à economia de mercado provocou uma alteração profunda nas relações de preços entre produtos industriais e commodities agrícolas e minerais, em favor destes últimos (Gráfico 1). Essa nova dinâmica de preços nos mercados mundiais, uma teoria da Cepal às avessas, provocou uma incrível mudança nas contas de nosso comércio exterior, com o aparecimento, a partir de 2004 , de saldos comerciais elevadíssimos (Gráfico 2).

Essa nova dinâmica permitiu ao Brasil passar em poucos anos de uma condição de um país endividado no exterior para uma nação que hoje tem mais ativos em moeda estrangeira do que sua dívida externa total (Gráfico 3). Foi essa mudança nas nossas contas externas que criou as condições iniciais - uma moeda nacional forte e estável - para o aparecimento dos frutos de uma política econômica correta mantida por um longo período, como citado anteriormente. Muitos analistas no Brasil - e o próprio presidente Lula costumam associar os bons ventos de hoje em nossa economia a uma interferência divina em favor do ex-líder sindical do ABC paulista. Mas se alguma intervenção externa, embora não de caráter divino, pode ser associada ao novo Brasil que aparece no cenário internacional, esta se deve a Deng Xiaoping, líder comunista chinês que liderou as reformas econômicas na China depois da morte do Grande Timoneiro.
[1] "Doença holandesa" é uma expressão que caracteriza as distorções causadas na economia de um país pela taxa de câmbio muito valorizada em função das exportações de um produto escasso nos mercados mundiais; nesta situação, uma parte importante do tecido produtivo do país sofre em função da perda de competitividade decorrente da taxa de câmbio valorizada.

[2] A estabilidade dos preços, a responsabilidade fiscal e a abertura econômica entre eles. 


\section{GRÁFICO I}

Preços das commodities - CRB

Alimentos e Produtos Industriais - Índices US\$ 1967=100

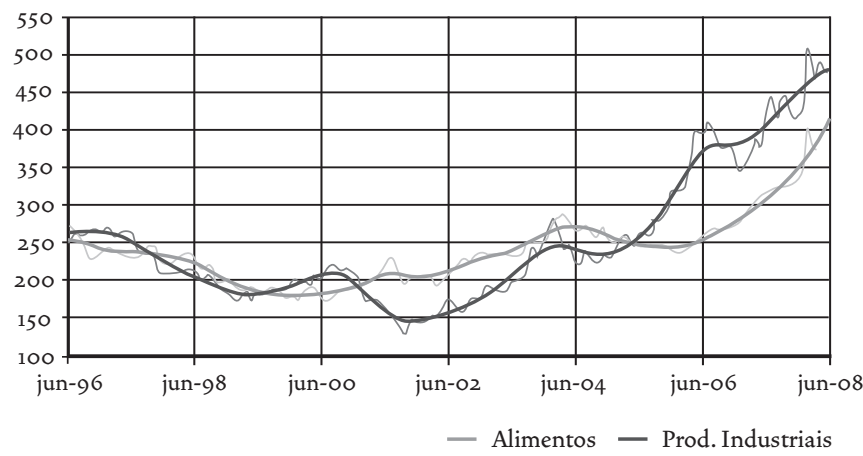

Fonte: Bioomberg. Elaboração: Quest Investimentos.

\section{GRÁFICO 2}

Importações, Exportações e Saldo Comercial US\$ Bilhões - Acum. 12 meses

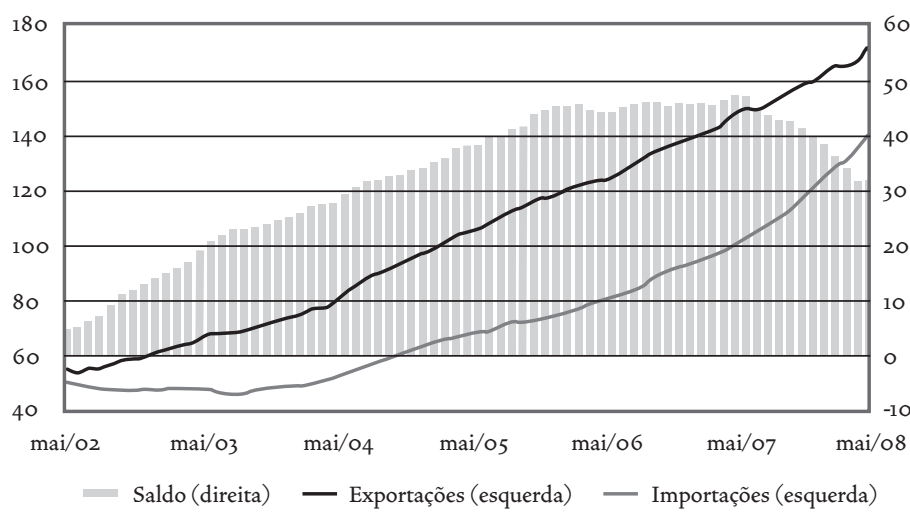

Fonte: Funcex. Elaboração: Quest Investimentos.

\section{COMO O CRESCIMENTO CHINÊS CHEGOU AO BRASIL}

A abertura econômica chinesa, com uma combinação de dirigismo estatal e economia de mercado, gerou um período de extraordinário crescimento, muito superior ao verificado no Japão do pós-guerra. Entretanto, como a dimensão da economia chinesa era muito pequena, apenas a partir da virada do século as suas importações de matérias-primas passaram a influenciar os preços internacionais. Nas contas externas brasileiras, o aumento dos preços de nossas exportações de produtos primários só aparece de forma significativa por ocasião das eleições presidenciais de 2002. Mas esta ocorreu sem que a 


\section{GRÁFICO 3}

Dívida externa líquida (privada e pública) brasileira

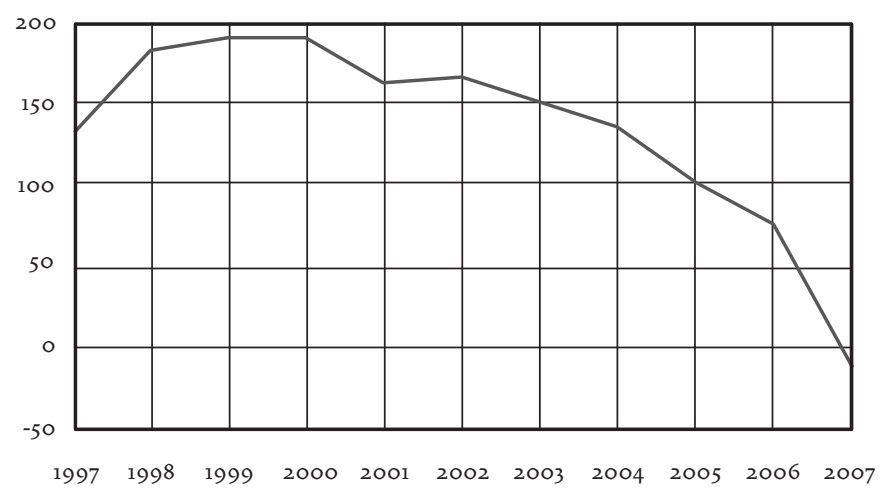

Fonte: BCB. Elaboração: Quest Investimentos

opinião pública tomasse contato com essa mudança. Por esse motivo, Lula foi eleito fazendo uma crítica duríssima contra o baixo crescimento do segundo mandato de Fernando Henrique e com promessas de mudanças radicais na política econômica.

Eleito, não levou adiante seu programa. O medo generalizado dos mercados em relação a seu governo provocou — ainda em 2002 - o colapso do real nos mercados de câmbio, criando as condições para a volta da inflação de dois dígitos. Lula, aconselhado por seu ministro da Fazenda, sancionou a aplicação, pelo Banco Central, de uma dose fortíssima do xarope dos juros altos. Por outro lado, assegurou aos mercados que não mudaria, na sua essência, a política econômica de seu antecessor. Este "cavalo de pau" na economia, na expressão do então ministro José Dirceu, foi vendido dentro do PT como sendo apenas um movimento tático antes da aplicação de uma nova política econômica mais à frente.

Em decorrência dessa decisão, o ano de 2003 foi de forte desaceleração econômica, com queda da atividade, aumento do desemprego e redução do valor real dos salários. O momento mais forte desse ciclo de contração ocorre no primeiro trimestre de 2004, quando as críticas contra o ministro da Fazenda atingiram seu ponto culminante. Sob a liderança do ministro José Dirceu - o mesmo que defendeu a mudança de rumo um ano antes - ensaiou-se uma tentativa de substituir Palocci no comando da economia e voltar às promessas da campanha eleitoral. $O$ ponto culminante deste movimento ocorreu em junho de 2004, quando o Dieese informou que o índice de desemprego do mês de maio havia sido o maior de toda a série histórica deste indicador.

Mas, neste momento de confrontação dentro do governo, o comércio exterior brasileiro já mostrava o crescimento quase explosivo de 
nossas exportações e o aparecimento de um excedente de dólares no mercado de câmbio nunca visto anteriormente. A inflação começava a ceder sob o peso dos juros, mas é o impacto do real forte que cria as condições para uma redução expressiva e continuada dos índices de preços. Era a vitória de Palocci e o início de uma fase incrível de crescimento da renda do brasileiro mais pobre (Gráfico 4), o que daria a Lula uma blindagem para enfrentar as crises políticas que se seguiram.

Com a saída do governo do todo-poderoso chefe da Casa Civil, inicia-se o período de dominância do ministro Palocci no governo e a consolidação da política econômica definida nos governos Fernando Henrique. Os frutos de um longo período de continuidade de uma política econômica coerente finalmente apareciam.

\section{O CRESCIMENTO CHINÊs COMO ÂNCORA PARA O BRASIL}

O crescimento da China tem sido fenomenal, em uma lógica de convergência acelerada para níveis de renda percapita mais altos, que tem arrastado o resto da Ásia e todos os países que de alguma forma tenham algum papel a desempenhar nesse processo. O ciclo econômico chinês tem se dado ao redor de uma tendência de crescimento muito forte, que ainda deve permanecer por alguns anos. A seqüência, ano após ano, ao longo de quase três décadas, de taxas de crescimento próximas a 10\% ao ano gerou massa crítica suficiente para tornar a China o novo pólo dinâmico global. A China ainda é menor - e continuará sendo por muito tempo - que os Estados Unidos em termos absolutos, mas a velocidade de crescimento é tal que sua contribuição para a expansão da economia mundial já é maior que a norteamericana. Pela primeira vez, em 2007 , o aumento em valor das vendas no varejo foi maior na China que nos Estados Unidos.Apesar dos riscos de desaceleração da economia em muitos países da Ásia, o elemento de convergência estrutural dos países ainda atrasados desta região parece ter atingido massa crítica suficiente para impulsionar a demanda por infra-estrutura e consumo em valores muito substanciais nos próximos anos.

Ameaça para muitos, oportunidades para outros, entender a questão chinesa é fundamental para qualquer planejamento estratégico, no nível empresarial ou nacional. O trabalhoé tão mais difícil quanto mais o país progride e muda, também com grande velocidade, condicionado pela rápida urbanização. O mercado interno chinês devora vorazmente quantidades antes inimagináveis de energia, matérias-primas industriais e, cada vez mais, commodities agrícolas. Os preços relativos das commodities cresceram pelo aumento da demanda nos países em desenvolvimento é razoável esperar que se mantenham altos por muito tempo até que a oferta consiga responder aos preços. Esta resposta tem sido 


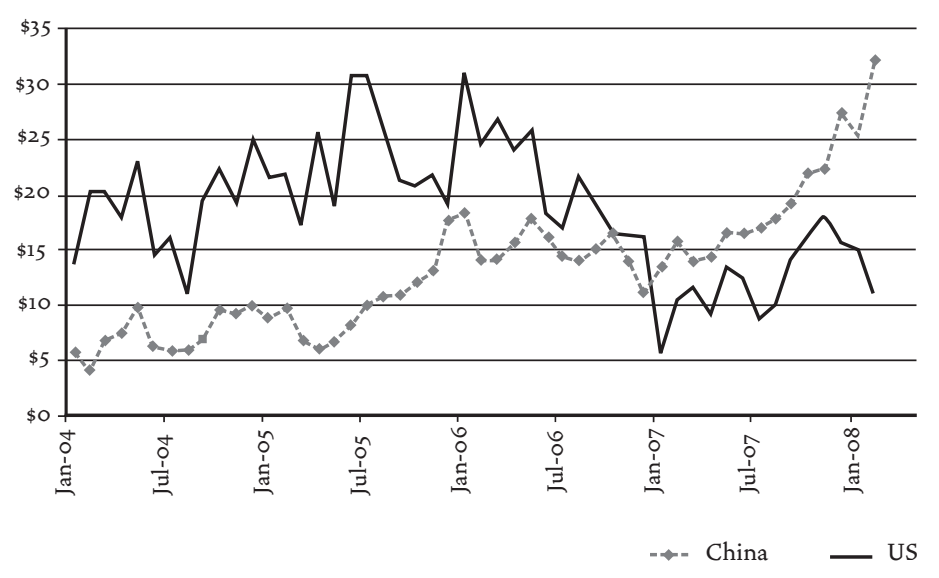

Fonte: Morgan Stanley

dificultada pelo aumento acelerado do custo marginal de novos projetos, que resulta em retorno baixo de novos investimentos. Com isso, os estoques de ampla parcela de recursos naturais permanecem em níveis muito reduzidos, a despeito da escalada de preços dos últimos anos. Além disso, o investimento em extração mineral e geração de energia tem sido, em muitos casos, dificultado por crescentes restrições impostas pelos governos nacionais à exploração pelo setor privado, o que é uma questão geopolítica de alta complexidade.

No caso de energia, por exemplo, o perfil de consumo chinês aindaé muito voltado para o setor industrial e apenas agora a parcela destinada ao transporte è infra-estrutura comercial e residencial, majoritária em países de renda mais alta, começa a ganhar espaço. A convergência do perfil de consumo chinês para o de países mais desenvolvidos e o forte investimento em infra-estrutura, estimado em mais de US $\$ 8$ trilhões nos próximos dez anos e que tem se acelerado no interior do país com dezenas de milhares de quilômetros de rodovias em construção, implica um grande crescimento da demanda de energia nos próximos anos ${ }^{3}$.

A AIE estima que em 2006 a demanda chinesa ultrapassou a da Europa e deve atingir o nível dos Estados Unidos na próxima década, muito mais rápido do que havia estimado em 2002. Na parte de commodities metálicas, o mesmo acontece.

Este cenário para os próximos anos deve garantir ao Brasil a continuidade dos preços elevados das commodities agrícolas e minerais que representam parte importante de nossa exportação, inclusive petróleo4. Sustentado por estes preços, o resultado de nossas exportações permite a continuidade do processo de abertura da economia, elemento fundamental para a manutenção da inflação dentro das metas do Banco Central e para a continuidade dos investimentos em nossa indústria via
[3] Ver sobre esses assuntos três estudos da Goldman Sachs: "The revenge of the old 'political' economy" (março de 2008), "\$100 oil reality part 2: Has the super-spike end game begun?" (maio de 2008) e "Building the World: Mapping the Infrastructure Demand" (abril de 2008).

[4] A manutenção do preço do petróleo em nível elevado é fundamental para viabilizar a exploração dos campos recém-descobertos na chamada camada pre sal. 


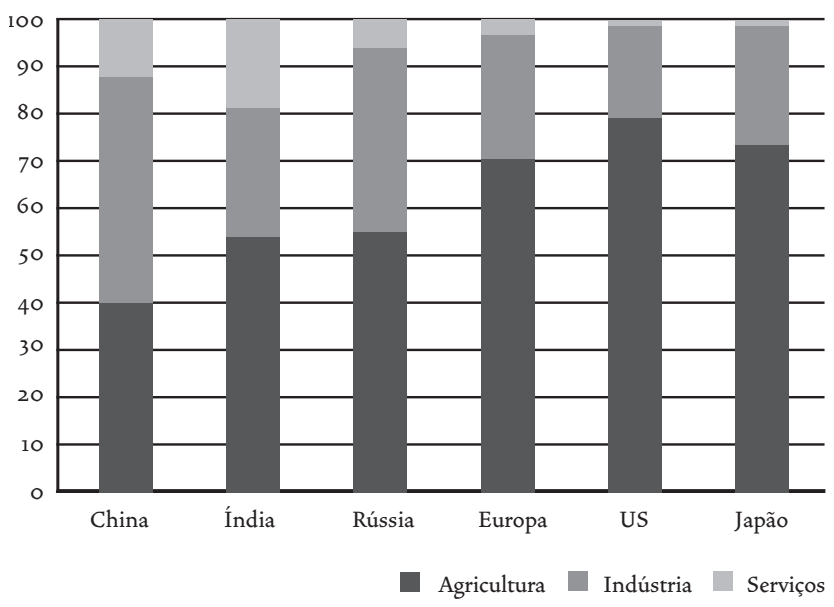

Demanda energética por setor (2005)

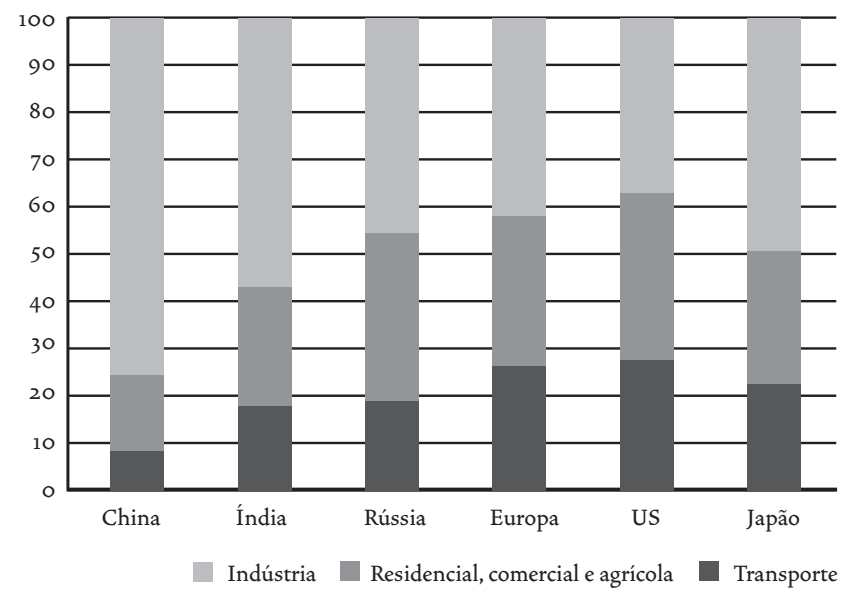

Fonte:Agência Internacional de Energia (AIE)

importações de equipamentos e máquinas. Caso se confirmem as projeções sobre a produção de petróleo nos novos campos recém-descobertos, esta ligação entre o crescimento da demanda chinesa e nosso comércio exteriorvai ficar ainda mais reforçada, pelo aparecimento de um saldo expressivo nas exportações líquidas de petróleo. Segundo estimativas da Petrobras, este excedente pode chegar a U $\$ 40$ bilhões em 2015.

\section{COMO AS MUdANÇAS DE NOSSAS CONTAS}

\section{EXTERNAS AFETARAM A ECONOMIA BRASILEIRA}

A relação entre o fortalecimento de nossas contas externas e o novo dinamismo do crescimento econômico brasileiro deu-se por vários canais microeconômicos. O primeiro deles foi o do impacto da valorização do real nos mercados de câmbio - movimento gerado pela 


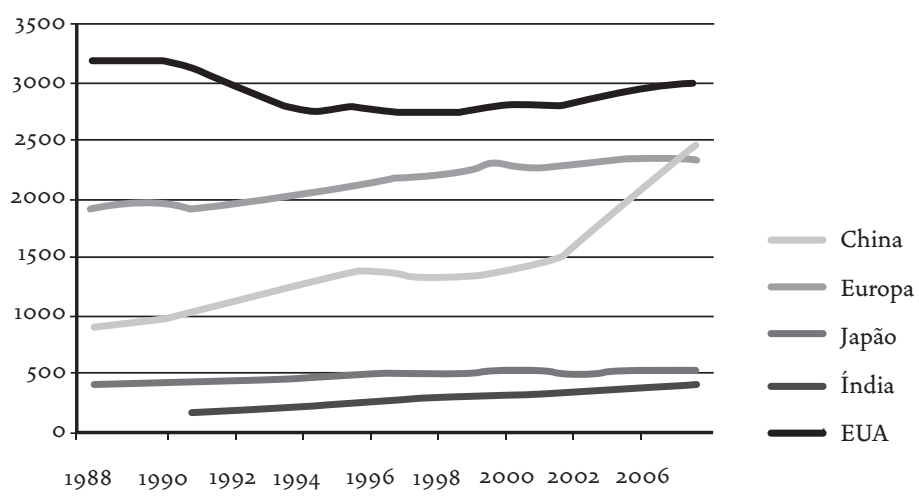

Fonte: Agência Internacional de Energia

incrível sobra de dólares nas mãos dos exportadores - na estabilização da inflação em 2004.A desvalorização de nossa moeda, em função da fuga de capitais que se seguiu ao fortalecimento da candidatura de Lula a partir de julho de 2002 , provocou um choque inflacionário de grandes proporções ao longo de 2003. Como vimos, o Banco Central respondeu com um aumento vigoroso dos juros, provocando uma profunda desaceleração da economia.

Um segundo canal entre o fortalecimento das contas externas brasileiras e a aceleração de nosso crescimento deu-se pelo aumento do poder de compra do consumidor, no início expressivamente nos de baixo poder aquisitivo, principalmente dos que ganhavam até dois salários mínimos e que representam quase $50 \%$ da população.

Embora iniciado nas camadas de renda mais baixas, este processo de aumento de renda expandiu-se posteriormente para as outras classes,

\section{GRÁFICO 4}

Salário Mínimo Nominal/Cesta Básica

Mensal e Media Móvel I2m

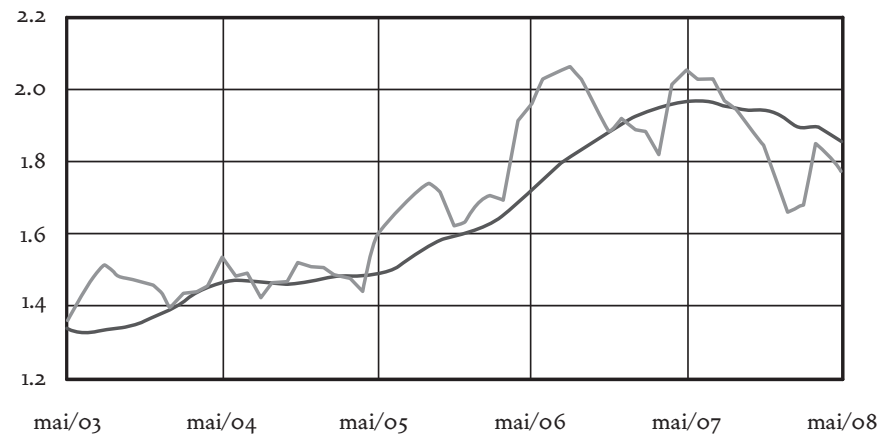


principalmente pelo aumento dos empregos a partir de $2005 / 2006.0$ Gráfico 5 mostra as duas ondas de aumento do poder aquisitivo do consumidor medidas pelas vendas ao varejo por região geográfica.

\section{GRÁFICO 5}

PMC (Vendas do Varejo) - Regiões

Var. Mensal interano (na tendência*)

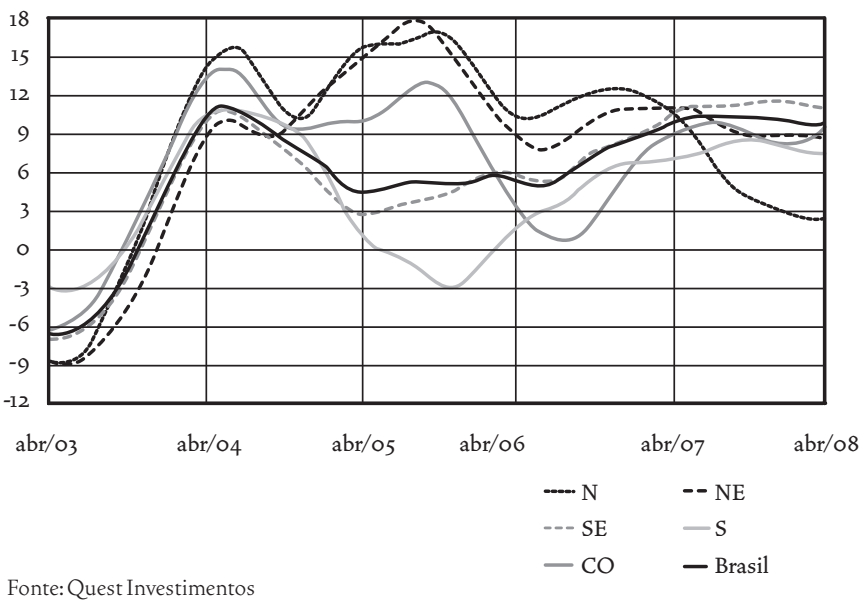

O terceiro canal entre a melhora nas contas externas e o novo dinamismo da economia brasileira aparece quando o sistema bancário começa expandir suas operações de crédito. Em um ambiente de maior confiança, os bancos brasileiros finalmente assumem seu papel de fornecedores de crédito a empresas e pessoas físicas. Esta mudança de comportamento aumenta de forma importante o poder de consumo dos salários via crédito para a compra de bens. Isto ocorre principalmente a partir de 2005, com o aumento do volume de crédito disponibilizado pelos bancos com um aumento significativo dos prazos das operações e redução do valor das prestações.

Finalmente, a conjugação de um forte aumento do consumo das famílias a um ambiente de maior segurança em relação à inflação em função do aumento da oferta de bens pelo canal das importações levou as empresas brasileiras a se decidirem por um aumento significativo de seus investimentos. Perdendo participação para as importações em um mercado em forte expansão, esta reação representou o último elo na reconstrução de nosso crescimento econômico sustentado.

Esta maior confiança das empresas em relação ao futuro produziu também um movimento na direção da formalização de seus negócios, inclusive nas relações trabalhistas, com reflexos extremamente positivos para a atividade econômica:

1. Aumento da segurança do emprego e maior acesso ao crédito bancário; 2 . Crescimento expressivo da arrecadação do INSS, reduzindo de forma importante o déficit do Tesouro;e3. Aumento da arre- 


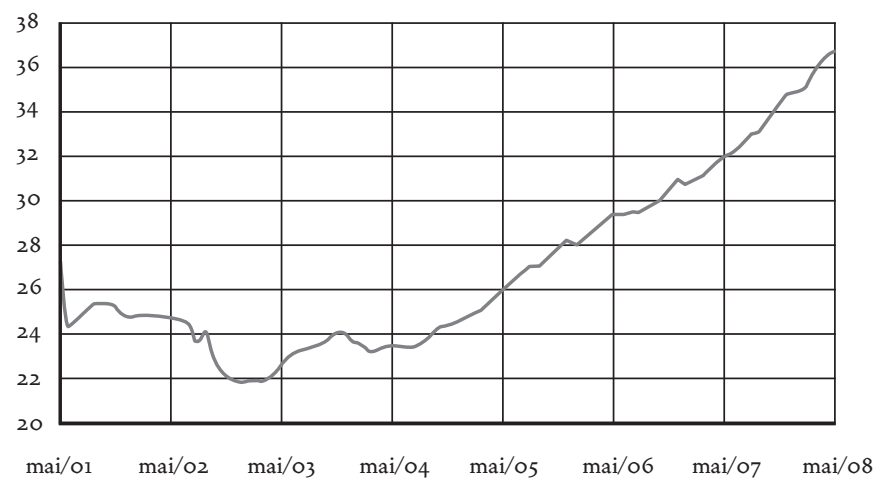

Fonte: BCB. Elaboração: Quest Investimentos

cadação de tributos em setores anteriormente com elevado grau de informalidade como o dos frigoríficos, por exemplo.

Pela primeira vez, em muitas décadas, chegamos ao fim de um ciclo completo - renda-crédito-consumo-investimento - de uma economia de mercado moderna. Os aumentos reais do salário mínimo entre 2004 e 2007 e a extensão do Programa Bolsa Família, em um ambiente de economia aberta e com uma sólida situação das contas cambiais, acabaram por funcionar como um estímulo keynesiano muito eficiente, antecipando a situação que vivemos hoje. Esta talvez seja a contribuição mais direta do governo Lula ao crescimento dos últimos anos.

Mas a normalização da economia brasileira trouxe também problemas comuns aos de outros países. A inflação que vivemos hoje, combinação de um superaquecimento da demanda interna e um choque de oferta externo - alimentos e petróleo - , vai levar a uma desaceleração do crescimento. Em 2009 e 2010 , em função da política monetária restritiva do Banco Central, deveremos crescer algo próximo a 3,5\% em média. Esta redução do crescimento faz parte dos ciclos de médio prazo de uma economia de mercado e deve ser entendida assim por nós, brasileiros. Afinal temos agora, depois de muito tempo de espera, uma economia de país sério, como disse o presidente Lula.

LUIZ CARLos MENDONÇA DE BARROS, engenheiro e economista, é economista-chefe da Quest Investimentos. Foi presidente do BNDES e ministro das Comunicações (governo FHC).

Recebido para publicação em 25 de junho de 2008.

\section{NOVOS ESTUDOS}

CEBRAP

81 , julho 2008

pp. $11-20$ 